\title{
Contrasting holm oak provenances show different field performance but similar resilience to drought events eight years after planting in a Mediterranean environment
}

\author{
Enrique Andivia (1), \\ Fabio Natalini ${ }^{(2)}$, \\ Manuel Fernández ${ }^{(2)}$, \\ Reyes Alejano ${ }^{(2)}$, \\ Javier Vázquez-Piqué ${ }^{(2)}$
}

(1) Forest Ecology and Restoration group, Departamento de Ciencias de la Vida, Universidad de Alcalá (Spain); (2) Departamento de Ciencias Agroforestales, Escuela Técnica Superior de Ingeniería, Universidad de Huelva (Spain)

\section{@ Enrique Andivia (e.andivia@gmail.com)}

Received: Jul 29, 2017 - Accepted: Jan 15, 2018

Citation: Andivia E, Natalini F, Fernández M, Alejano R, Vázquez-Piqué J (2018). Contrasting holm oak provenances show different field performance but similar resilience to drought events eight years after planting in a Mediterranean environment. iForest 11: 259-266. - doi: 10.3832/ifor2573011 [online 2018-03-29]

Communicated by: Tamir Klein

Diversification of genetic plant material in forest plantations is viewed as a promising strategy to promote forest adaptation and resilience to ongoing climate change. However, there is an intense debate about whether foreign populations might outperform local ones under new climatic conditions. Unfortunately, long-term experiments using contrasting provenances are scarce, especially in the Mediterranean region. In this context, the evaluation of the resistance and resilience of individuals from different provenances to drought can help to forecast their performance under different climate change scenarios, and therefore to establish guideline regarding plant material selection in reforestation projects. We evaluated the performance (survival and drought) and drought sensitivity of Quercus ilex saplings from two contrasting provenances growing during eight years in a common garden experiment. For this, we used a combination of dendroecological methods and water-relation measurements, such as leaf water potential $\left(\Psi_{\mathrm{pd}}\right)$, cuticular transpiration $\left(\mathrm{E}_{\mathrm{c}}\right)$, relative water content at the point of stomatal closure $\left(\mathrm{RWC}_{\mathrm{c}}\right)$ and specific leaf area (SLA). We also compared the resilience and resistance, in terms of radial growth to the intense drought event of 2012 between saplings from both provenances. Our results suggest a lack of idiosyncratic physiological response and growth sensitivity to drought between provenances. However, saplings from the drier provenance showed a superior performance in terms of survival and growth. Survival was greater in saplings from the dry provenance (100 vs. $91 \%)$. Mean annual basal area increment was also greater in saplings from the dry provenance $\left(158.8 \pm 13.5 \mathrm{vs} .96 .2 \pm 8.4 \mathrm{~mm}^{2}\right)$, which resulted in greater diameter eight year after planting $(47.5 \pm 2.8 \mathrm{vs} .38 .3 \pm 2.3 \mathrm{~mm})$. The lower values of $\Psi_{\mathrm{pd}}, \mathrm{E}_{\mathrm{c}}$ and SLA in the summer of the first two years after planting suggest that climatic conditions after planting rather than isolated drought events was the most critical period for the success of these saplings. In view of our results, the selection of plant material for forest plantation should be carefully evaluated in forest restoration projects, while priority should be given to those actions oriented to increase the early survival of local $Q$. ilex seedlings.

Keywords: Ecotypes, Quercus llex, Forest Restoration, Growth Stability, Waterrelation, Phenotypic Plasticity, Local Adaptations

\section{Introduction}

The Mediterranean region has been identified as a primary hotspot particularly vulnerable to climate change impacts (Giorgi 2006). Climate change is expected to trigger dramatic modifications to the structure and composition of Mediterranean forests through the alteration of growth, mortality and regeneration patterns of tree species (Sánchez-Salguero et al. 2012, Ruiz-Benito et al. 2013). Tree species can respond to changing climate conditions through a combination of phenotypic plasticity, adaptation and migration to more suitable areas (Bussotti et al. 2015). However, the rapidity of human-induced environmental changes may exceed the rates at which adaptation and migration naturally occur (Lindner et al. 2014). Species distribution models show that most Mediterranean tree species will experience a reduction of their potential distribution areas as a consequence of a northward shift of their optimum climate (Benito-Garzón et al. 2008). In this context, forest managers are facing real challenges in order to ensure the long-term maintenance of forest ecosystem services by making decisions in the present under a high uncertainty.

Ecophysiological responses of forest tree species to stress factors have showed not only a great inter-specific variation but also great intra-specific phenotypic plasticity and local genetic adaptations (Gratani et al. 2003, Gimeno et al. 2008, Andivia et al. 2012a). Provenance is based on the idea that populations of plant species are adapted to local and regional environmental conditions (Pluess et al. 2016). The establishment of new forests through reforestation has been traditionally conducted using native tree species and local seed sources under the notion of climate-related local adaptations (Savolainen et al. 2007). How- 
ever, changing environmental conditions can prompt a spatial mismatch between local populations and their optimal climate conditions. This uncertainty with respect to future performance of local populations under changing climate might represent a shift in the paradigm of "local is the best". In fact, diversification of genetic material used in forest restoration programs has been seen an adequate strategy to guarantee forest adaptation and resilience to new climate conditions (Aitken \& Whitlock 2013).

Management strategies oriented to guarantee the adaptation of forests to new climate conditions have gained increasing popularity during last decade (Schwartz et al. 2012). Assisted population migration (APM) is the human-mediated translocation of plant genetic resources to areas where future climate conditions are expected to be similar to those at which these populations were originally adapted (Aitken \& Whitlock 2013). The main benefit of implementing APM within forest management programs is the potential to maintain forest productivity and ecosystem services provision while reducing the vulnerability of forest ecosystems to climate change (Aitken \& Whitlock 2013). However, APM is not immune to an intense debate about potential risks and benefits of such an approach (see Bucharova 2017). Nonetheless, there is a lack of consensus regarding the fact that plants from foreign populations might outperform local ones under ongoing climate change (Benomar et al. 2016).

Common garden experiments in which the long-term performance of different seed sources are evaluated might help to shed light on the intrinsic response of different populations to stress factors, such as drought or frosts. Unfortunately, longterm experiments are scarce, especially in the Mediterranean region where most of the studies have been conducted under controlled conditions or using one-year-old seedlings (Andivia et al. 2012b). In this regard, tree-ring analysis can provide valuable information on provenance fitness over time through the analysis of radial growth response to climate (Leland et al. 2016). Moreover, the evaluation of the resistance and resilience of individuals from different provenances to drought can help to forecast their performance under the rising frequency of extreme events. Whether the integration of genotypes of drier provenances into mesic sites increases the resilience of forest plantations is a core issue in the open debate regarding the suitability of APM measures for the Mediterranean region.

In this study, we evaluated the performance and drought sensitivity of Quercus ilex subp. ballota (Desf.) saplings from two contrasting provenances growing during eight years in a common garden. Q. ilex is the late-successional evergreen oak mostly used in forest restoration programs in the
Mediterranean area (Rodá et al. 1999). However, these programs have enjoyed a very limited success due mainly to the vulnerability of Q. ilex seedlings to water stress during early life (Villar-Salvador et al. 2004). Q. ilex inhabits a broad range of environments along the Mediterranean basin, from warm and arid areas to dry and cold highlands, which suggests the presence of local adaptations and high phenotypic plasticity (Valladares et al. 2000). In fact, several studies have suggested a strong genetic control on the physiological response of Q. ilex to drought (Gratani et al. 2003, Pesoli et al. 2003, Gimeno et al. 2008, Andivia et al. 2012a). In Spain, 28 different provenances have been identified for $Q$. ilex (Alía et al. 2009). However, the Spanish legislation about plant material commercialization for reforestation sets out only recommendations, and not legal obligations regarding the use of provenances in forest plantations. In this context, understanding the contribution of local adaptation and within-population plasticity to the performance of tree species in response to drought events constitutes a key element in the design of forest restoration guidelines regarding plant material selection, especially under a changing environment.

Our main goal is to compare the response to drought events of $Q$. ilex saplings from two contrasting provenances in terms of water availability (dry vs. mesic provenance), planted in a common garden. For this, we combined the growth-climate response through the analysis of tree-rings with summer ecophysiological measurements of functional traits and water status parameters. We also assessed growth stability of both provenances following the most severe drought event occurred during the study period by analyzing resistance and resilience growth indices (Lloret et al. 2011). We hypothesized that: (i) plants from the mesic provenance will experience a strong growth constraint in dry years; (ii) plants from the dry provenance will show a better water status during summer; and (iii) plants from the dry provenance will be more tolerant and resilient to severe drought events.

\section{Material and methods}

\section{Plant material and experimental site}

In mid-autumn 2006, acorns of Q. ilex were collected from two Spanish provenances (Fig. 1): Región Extremadurense (37 $30^{\prime} \mathrm{N}, 07^{\circ} 19^{\prime} \mathrm{W}$; altitude $1125 \mathrm{~m}$ a.s.l.) and Sierras Béticas Orientales ( $37^{\circ} 55^{\prime} \mathrm{N}, 02^{\circ} 26^{\prime}$ W; altitude $1125 \mathrm{~m}$ a.s.l.). Acorns were collected from 25 randomly selected trees that where more than $80 \mathrm{~m}$ apart each other in an area of about 6 ha at each location. To guarantee that differences between provenances were due to genetic background rather than other factors related to mother trees, we selected only healthy trees of similar size. Region Extremadurense (hereafter mesic prove- nance) is the core population of Q. ilex in Spain (35.8\% of the total area occupied by Q. ilex in Spain), while Sierras Béticas Orientales (hereafter dry provenance) represents the $2.3 \%$ of the Q. ilex surface (Alía et al. 2009). Both provenances are on acid soils (Cambisols) and show a similar summer drought period of 3 months. The dry provenance had a typical Mediterranean continental climate with colder winters but with lower annual rainfall than the mesic provenance (306 and $558 \mathrm{~mm}$, respectively). Acorn mass did not significantly differ between provenances (3.89 $\pm 0.60 \mathrm{~g}$ and $4.28 \pm 0.97$ for the mesic and dry provenances, respectively). Acorns were stored in a cold chamber at $4{ }^{\circ} \mathrm{C}$ until they were pre-germinated at $20^{\circ} \mathrm{C}$, on wet perlite.

In March 2007, 440 healthy and germinated acorns (220 per provenance) were sown in 11 Plasnor $^{\circledR}$ trays (45 cavities of 300 $\mathrm{cm}^{3}$ per tray) filled with sphagnum peat and placed in a nursery $\left(37^{\circ} 12^{\prime} \mathrm{N}, 06^{\circ} 55^{\prime} \mathrm{W}\right.$; altitude $23 \mathrm{~m}$ ) under a shade-cloth that reduced radiation by $\sim 50 \%$. Each tray contained 20 acorns from each provenance (five cavities per tray were not used). All trays were well watered with tap water, and a constant fertilization regimen was applied following the recommendation for commercial cultivation of holm oak (VillarSalvador et al. 2013). The total fertilizer applied to each seedling over the nursery period was $97.5 \mathrm{mg} \mathrm{N}, 55.4 \mathrm{mg} P$ and $70.2 \mathrm{mg}$ K.

The planting site was located in a flat experimental plot of the University of Huelva in southwestern Spain $\left(37^{\circ} 12^{\prime} \mathrm{N}, 06^{\circ} 54^{\prime} \mathrm{W}\right.$ - Fig. 1) at $9 \mathrm{~m}$ a.s.l. The climate is Mediterranean coastal with mean annual precipitation and temperature of $541 \mathrm{~mm}$ and 16.7 ${ }^{\circ} \mathrm{C}$, respectively, and a pronounced dry and hot season from June to mid-September. Planting was conducted in February 2008. Seventy randomly selected seedlings (35 per provenance) were planted in seven lines (five plants per provenance and per line, randomly distributed), with a separation of $1 \mathrm{~m}$ among consecutive plants and 2 $\mathrm{m}$ among lines. At the time of planting, seedling were not significantly different in size; the mean height of seedlings was 14.6 $\pm 2.9 \mathrm{~cm}$ and $15.7 \pm 2.7 \mathrm{~cm}$ for the mesic and dry provenances, respectively.

\section{Water status and morpho-physiological measurements}

We measured predawn leaf water potential $\left(\Psi_{p d}\right)$, cuticular transpiration $\left(E_{c}\right)$, relative water content at the point of stomatal closure $\left(R W C_{c}\right)$ and specific leaf area (SLA) in eight randomly selected saplings per provenance in mid-July in 2008, 2009, 2011 and 2012. Because of the small size of plants during the first two years after planting, those saplings selected in 2008 were not used for 2009 measurements. $\Psi_{\mathrm{pd}}$ was measured in two mature leaves per sapling using a pressure chamber (Model 1000, PMS Instruments, Corvallis, OR, USA) 


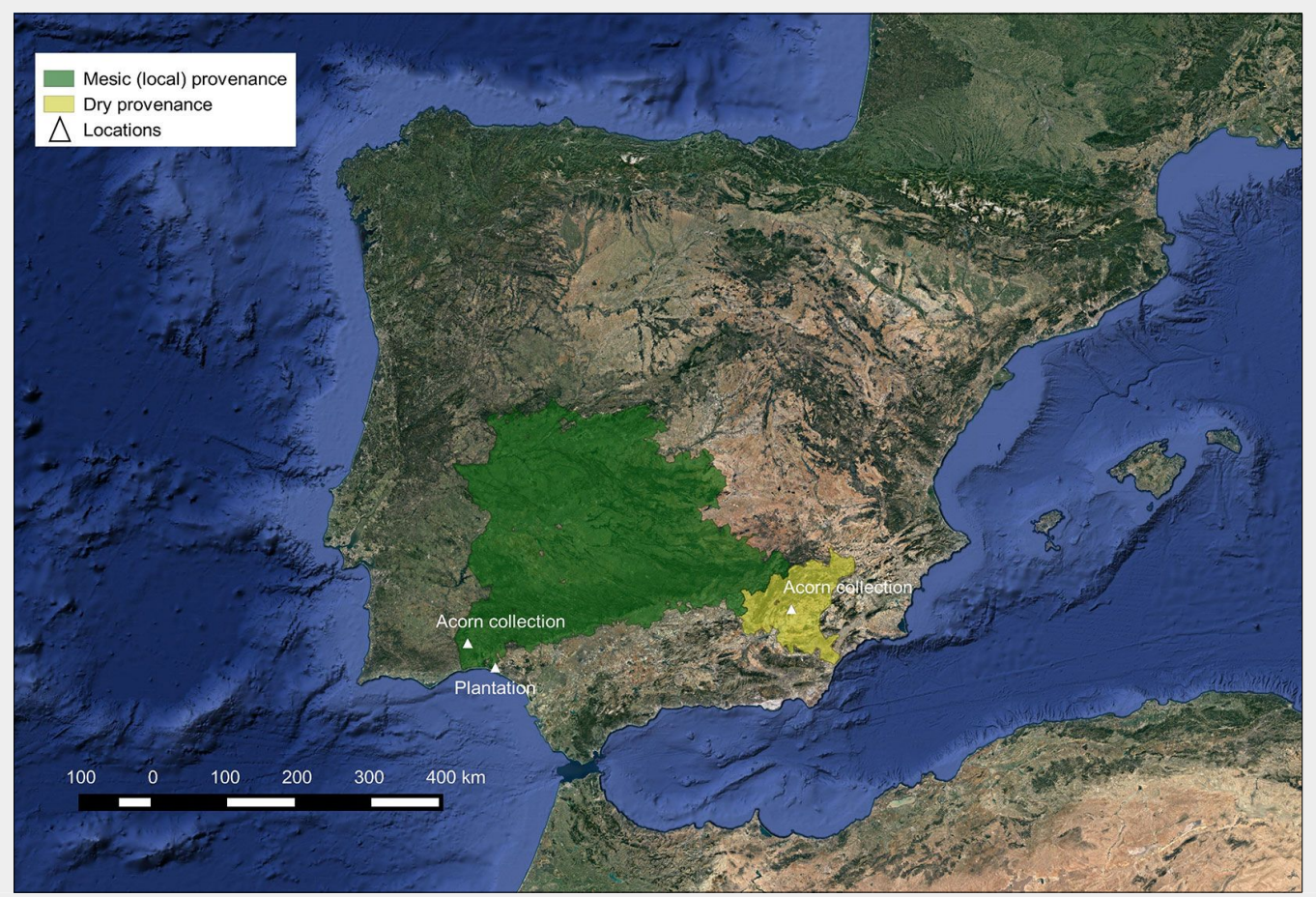

Fig. 1 - Map of the locations from which acorns were collected at each provenance (Acorn collection), and the location of the common garden in which seedlings were planted (Plantation). The shapefile of the different provenance regions was created by CIFOR-INIA (Madrid, Spain).

and following the method described by Scholander et al. (1965). $E_{c}$ and $R W C_{c}$ were evaluated in two mature leaves per sapling using the method of Quisenberry et al. (1982). Briefly, rehydrated leaves were placed abaxial surface down on a plastic mesh in a lighted laboratory at constant temperature $\left(22^{\circ} \mathrm{C}\right)$. The leaf fresh weights were measured at intervals of 5-10 minutes for a minimum of $7 \mathrm{~h}$. Afterwards, we calculated descending transpiration curves for each leaf, which were used to estimate $E_{c}$ and $\mathrm{RWC}_{\mathrm{c}}$. The projected leaf area $\left(\mathrm{LA}_{\mathrm{p}}\right)$ was measured in three mature leaves per sapling using ImageJ (different versions). SLA was calculated as the $\mathrm{LA}_{\mathrm{p}}$ divided by the dry weight of leaves (oven-dried at $75^{\circ}$ ( for $48 \mathrm{~h}$ ).

\section{Dendrochronological analyses}

In February 2016, eight years after plantation, the height and diameter of all living saplings (29 and 35 saplings for the mesic and dry provenance, respectively) were measured. Fifteen saplings per provenance were cut down (see Fig. S1 in Supplementary material). Saplings were selected according to the distribution of the sapling diameter classes (Fig. S2). For the bottom portion of each sapling's stem, we obtained four consecutive slices (thickness approximately $2 \mathrm{~cm}$ ). The cross-sections were air-dried and polished with progressively finer grits (60-600) to make the rings visible. Ring widths were measured in two perpendicular axes with Image (ver. 1.51h) after scanning slices at a resolution of 1200 dpi (HP Scanjet $300^{\circledR}$ ). Cross-dating was not necessary because all seedlings were planted at the same date and had the same age. We did not detect any missing ring in the dendrochronological series.

For each sapling, we averaged the ring width of the four cross-sections analysed (two axes per slice). To study the growth trend, tree ring-width series were converted into basal area increment (BAI), assuming stem growth is approximately concentric (Biondi \& Qeadan 2008). BAI provides a biologically meaningful variable showing growth trends independently of tree size. BAl computation was done in $R$ ver. 3.2.5 using the dplR package (Bunn 2008).

\section{Drought events characterization and growth stability}

To identify the main drought events that might affect sapling growth in the study period, we used the Standardised Precipitation-Evapotranspiration Index (SPEI) developed by Vicente-Serrano et al. (2010). The SPEI is a multi-scalar drought index based on a simple climatic water balance (monthly differences between precipitation and reference evapotranspiration), which is intended to determine the onset, duration and magnitude of drought conditions with respect to normal conditions in a given area (see Vicente-Serrano et al. 2010 for details). The SPEI index has shown a superior performance to capture the drought impacts on forest growth compared to other drought indices (Vicente-Serrano et al. 2010). To characterize the climatic conditions yearly, in terms of water availability, the SPEI index at a time scale of 12 months was calculated using the package SPEI in $R$ ver. 3.2.5. Climatic data were obtained from a weather station located $12 \mathrm{~km}$ far from the experimental plot $\left(37^{\circ} 08^{\prime} \mathrm{N}, 06^{\circ}\right.$ $47^{\prime} \mathrm{W}$ ). Since 2002, eight years have shown negative SPEI values in the planting area (i.e., dry years) with the strongest drought event in 2005 (SPEI = -1.61 - Fig. S3 in Supplementary material). During the study pe- riod, five of the eight years had negative SPEI values (Fig. S3), and 2012 was identified as the driest year (SPEI =-0.91). Annual SPEI values were correlated with annual rainfall $(r=0.89)$.

To assess growth stability to the drought event occurred in 2012, the resistance (Rt) and resilience $(R s)$ indices were calculated following Lloret et al. (2011 - eqn. 1, eqn. 2):

$$
\begin{aligned}
& R t=\frac{D r}{P r e D r} \\
& R s=\frac{\text { Post } D r}{\text { PreDr }}
\end{aligned}
$$

Resistance is the capacity to sustain predrought (PreDr) growth levels during the year of the drought event ( $\mathrm{Dr}$ - eqn. 1), whereas resilience is the capacity to reach pre-drought growth rates after drought event occurrence (PostDr - eqn. 2). Rt and $R s$ indices were calculated for each sapling from its BAl series. Growth during the drought event corresponds to the BAI in 2012. Pre-drought and post-drought growth were calculated as the mean annual BAl in the 2 years before and after 2012, respectively. These indices were calculated in $R$ ver. 3.2.5 using the pointRes package (Van Der Maaten-Theunissen et al. 2015).

\section{Data analysis}

We analyzed differences in water status and physiological parameters between provenances at the different measurement dates by using a $t$-test. Differences in size (height and diameter) at the time of felling, and in Rt and Rs indices between saplings of both provenances were also assessed by a $t$-test. Significant differences were considered at $p<0.05$.

To evaluate BAl trends, we used a mixed linear model in which sapling age, prove- 
nance and SPEI were the main effects. We applied a mixed model because growth series results in non-independency among observations within the same individual. Thus, sapling identity was considered as a random effect. To assess whether saplings of the two provenances show different growth response to water availability, the interaction between provenance and SPEI was included as a fixed effect. BAI was logtransformed because it showed a skewed distribution. To identify the best-supported model we built all possible model combinations from the full model considering both the main effects and the interactions between provenance and SPEI. However, as we were interested in extracting the age effect on growth, we included the sapling age as main effect in all the alternative models. Model selection was performed following the information-theoretic approach, based on minimizing the Akaike's Information Criterion corrected for small sample sizes (AICC) which was used as indicator of both parsimony and likelihood (Burnham \& Anderson 2002). Alternative model were fitted by the Maximum Likelihood method (ML), whereas the parameter of the selected model were estimated using the restricted maximum likelihood (REML). The pseudo- $R^{2}$ was used to estimate the variance explained by fixed and random factors (Nakagawa \& Schielzeth 2013). All statistical analyses were performed in $R$ ver. 3.2.5 using the package Ime4 (Bates et al. 2015).

\section{Results}

Sapling water status, size and mortality We found no significant differences between provenances in $\Psi_{\mathrm{pd}}, \mathrm{E}_{\mathrm{c}}, \mathrm{RWC}_{\mathrm{c}}$ and SLA for each of the four evaluated summers (Fig. 2, Tab. S1 in Supplementary material). Mean values ( $\pm \mathrm{SE}$ ) of water status parameters were $-1.96 \pm 0.36 \mathrm{MPa}$ for $\Psi_{\mathrm{pd}}$, $88.90 \pm 15.43 \mathrm{mmol} \mathrm{H}_{2} \mathrm{O} \mathrm{kg}^{-1} \mathrm{~s}^{-1}$ for $\mathrm{E}_{\mathrm{c}}, 80.28$ $\pm 5.71 \%$ for $\mathrm{RWC}_{c}$, and $3.57 \pm 0.33 \mathrm{~m}^{2} \mathrm{~kg}^{-1}$ for SLA. However, water status parameters differed in relation to the year. $\Psi_{\mathrm{pd}}, \mathrm{E}_{\mathrm{c}}$ and SLA increased over the study period, with lower values in the summer of the first two years after planting (Fig. 2). On the other hand, $\mathrm{RWC}_{\mathrm{c}}$ was lower in the summer of 2012 when compared with the previous summers (Fig. 2C).

Eight years after planting, saplings showed significant differences in diameter $(p=$ 0.015 ) between provenances but not in height ( $p=0.760$ - Fig. S4 in Supplementary material). Saplings from the dry provenance had a greater diameter than those from the mesic provenance; $47.5 \pm 2.8 \mathrm{~mm}$ vs. $38.3 \pm 2.3 \mathrm{~mm}$ (mean $\pm \mathrm{SE}$ ), respectively. Mean height ( \pm SE) was $243.1 \pm 72.7 \mathrm{~cm}$ and $237.9 \pm 61.6 \mathrm{~cm}$ for the dry and mesic provenances, respectively. The diameter class distribution was similar for both provenances (Fig. S2 in Supplementary material); more than $50 \%$ of the saplings had a diameter between 30 and $50 \mathrm{~mm}$. However, the dry provenance showed a high proportion of saplings within the upper diameter classes. Mortality was very low eight years after planting with only six dead saplings $(8.57 \%)$, interestingly all of them were from the mesic provenance.

\section{Growth patterns}

The most parsimonious model describing sapling growth included the age of saplings, the provenance and the SPEI as main effects (Tab. 1). The selected model explained $81 \%$ (conditional pseudo- $\mathrm{R}^{2}$ ) of the total variance of sapling BAI, while the fixed effects explained about $76 \%$ (marginal pseudo- $R^{2}$ ) of the variance. The inclusion of the interaction between provenance and SPEI did not significantly improve model fitting (Tab. 1). Among the fixed effects, the age of saplings was the main factor explaining sapling growth (Tab. 1, Fig. 3). Both, provenance and SPEI explained a significant part of the variability of sapling BAI, although the effect of SPEI was more important according to the increment in AICC for those models in which SPEI $(\triangle \mathrm{AICC}=39.75)$ or provenances were ignored $(\triangle A I C C=8.91)$. The effect of SPEI on BAI was positive (estimated slope $=0.39 \pm 0.06$ ), which means that predicted sapling growth was lower in dry years (Fig. 3). On the other hand, mean BAl was greater for the dry provenance (151.8 \pm 13.5 $\left.\mathrm{cm}^{2}\right)$ than for the mesic provenance ( $96.2 \pm$ $\left.8.4 \mathrm{~cm}^{2}\right)$.

\section{Growth stability components}

Growth stability components (resistance a)

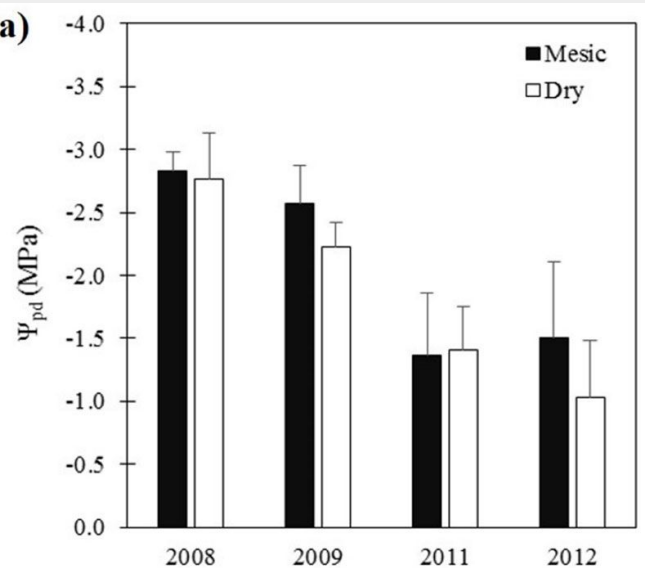

c)

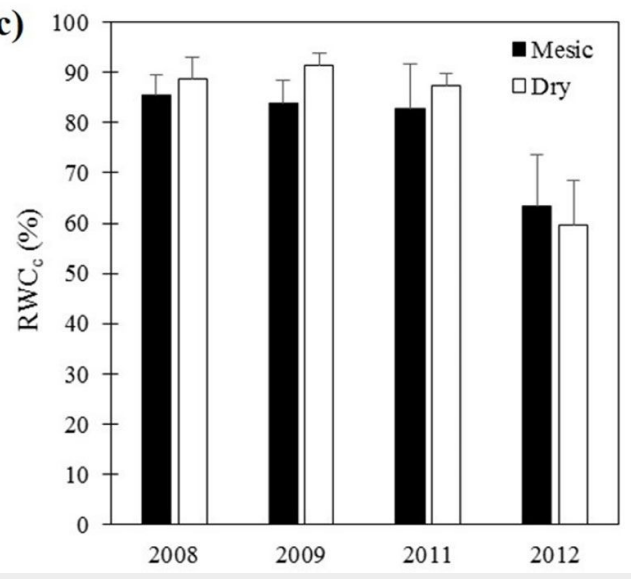

b)

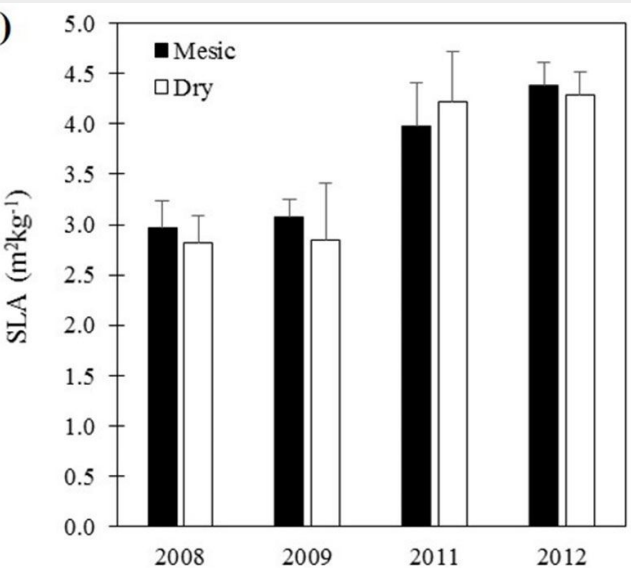

d)

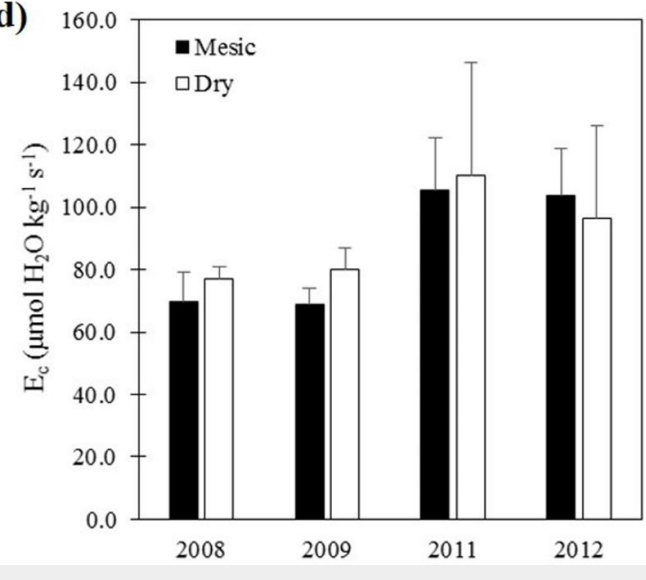

Fig. 2 - Mean values $\pm \mathrm{SE}$ $(n=8)$ of: (a) predawn leaf water potential $\left(\Psi_{\mathrm{pd}}\right),(\mathrm{b})$ specific leaf area (SLA), (c) relative water content at the point of stomatal closure $\left(R W C_{c}\right)$ and $(d)$ cuticular transpiration ( $\left.E_{c}\right)$ of $Q$. ilex sapling from two contrasting provenances measured in mid-July in 2008 , 2009, 2011 and 2012. 
Fig. 3 - (a) Accumulated basal area increment (BAI) \pm SE $(n=15)$ of Q. ilex saplings from two contrasting provenances growing during eight years in a common garden. (b) and (c) show the predicted effect of sapling age and Standardized Precipitation Evapotranspiration Index (SPEI) on sapling basal area increment, respectively.

Grey areas represent confidence intervals ( $95 \%$ ) of model predictions.

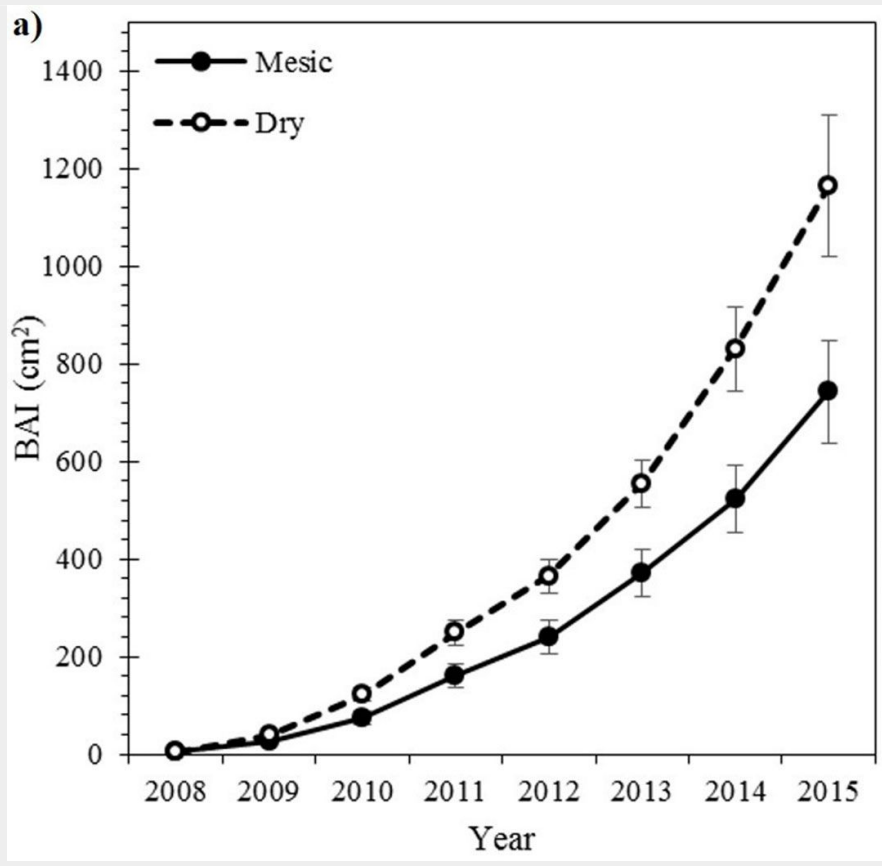

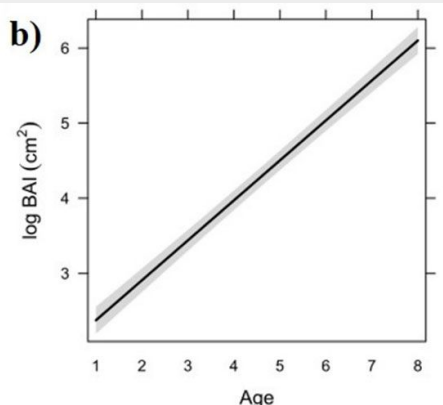

c)

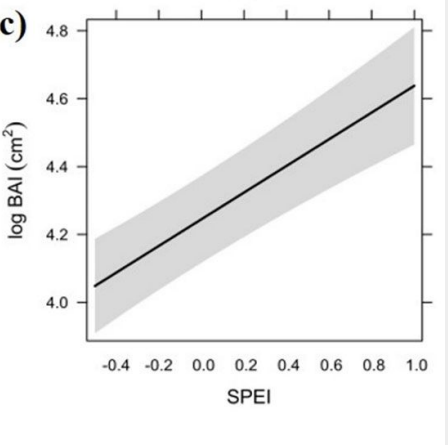

and resilience) did not significantly vary between provenances for the drought event of 2012 (Fig. 4). Resilience index was slightly higher in saplings from the dry than from the mesic provenance $(1.02 \pm 0.12$ vs. $0.91 \pm$ 0.09 ), while the opposite was observed for the resistance index $(0.92 \pm 0.11$ vs. $0.96 \pm$ 0.06). Resistance index showed a growth decline of $8.69 \%$ for both provenances. Despite resilience index did not differ between provenances, saplings from the dry provenance showed in 2014 similar growth levels to those two years before the drought event of 2012, while saplings from the mesic provenance reached previous growth levels in 2015. Resistance and resilience indexes were positively correlated $(p<0.001, r=0.669)$, indicating than those saplings more resistant to drought events were also the more resilient.

\section{Discussion}

Overall, our results indicate that holm oak saplings from contrasting provenances do not respond differently to drought events eight years after planting in a common garden. However, there are interesting aspects in our results that suggest an idiosyncratic field performance between provenances, which could have practical implications for forest restoration programs.

Several studies support that physiological response of Quercus species to drought might be linked to genetic adaptations of individual provenances (Gratani et al. 2003, Gimeno et al. 2008, Andivia et al. 2012a). On the contrary, we found that Q. ilex provenances similarly react to drought in terms of both physiological parameters related to water relations and growth. These results might suggest a high adaptive phenotypic plasticity in this species, which would allow the morpho-physiological acclimation of individuals from different pop- ulations to changed environmental condi- the risk of species loss due to rapid climate tions (Bussotti et al. 2015). Both local adap- fluctuations, such as ongoing climate tations of functional traits and phenotypic change (Savolainen et al. 2007). However, plasticity play a pivotal role in decreasing the implementation of APM in forest

Tab. 1 - Comparison of alternative mixed linear models to assess the effect of sapling age, provenance (Prov) and Standardized Precipitation Evapotranspiration Index (SPEI) on sapling basal area increment. Model selection was performed based on the corrected Akaike's Information Criterion $\left(\mathrm{AIC}_{\mathrm{c}}\right) . \Delta \mathrm{AIC}_{\mathrm{c}}$ refers to the difference in $\mathrm{AIC}_{\mathrm{c}}$ between the alternative model and the most parsimonious model (i.e., $\triangle A I C_{c}=0$ ).

\begin{tabular}{lccc}
\hline Alternative models & $\mathrm{AIC}_{\mathrm{c}}$ & $\Delta \mathrm{AIC}_{\mathrm{c}}$ & pseudo- $^{2}$ \\
\hline Age + Prov $\times$ SPEI & 437.39 & 1.93 & 0.81 \\
Age + Prov + SPEI & 435.46 & 0 & 0.81 \\
Age + Prov & 475.21 & 39.75 & 0.77 \\
Age + SPEI & 444.37 & 8.91 & 0.81 \\
Age & 484.12 & 48.66 & 0.77 \\
null & 785.59 & 350.13 & 0.20 \\
\hline
\end{tabular}

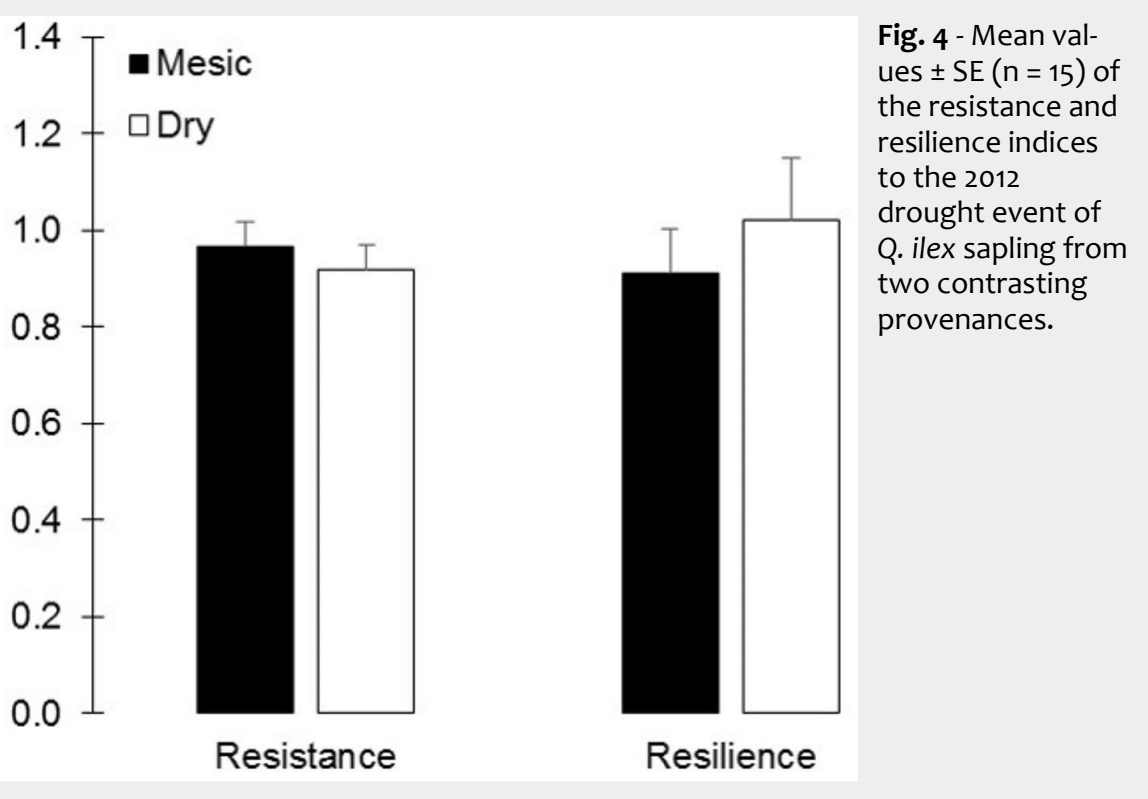


restoration projects should rely on the fact that population adaptation to environmental conditions would overcome phenotypic plasticity among populations. In fact, this represents a core issue for the proper selection of plant material in restoration programs, especially for widely distributed species such as Q. ilex, whose distribution range encompasses a broad environmental heterogeneity, potentially resulting in wider fundamental niches and greater phenotypic plasticity (Valladares et al. 2007). Indeed, Gimeno et al. (2008) pointed out that plasticity in this species is more important than adaptation and genetic differences among population in response to environmental stress. However, other studies have found a higher drought tolerance and lower SLA in Q. ilex and Q. suber seedlings from drier provenances (Gratani et al. 2003, Pesoli et al. 2003, Ramírez-Valiente et al. 2011).

During the studied period, the most intense drought event occurred in 2012. The negative impact of the drought event of 2012 on tree growth has been also reported in Mediterranean pine forests in southern Spain (Marqués et al. 2016). In our study, saplings responded to water availability by reducing radial growth, but no significant differences between provenances in inter-annual growth variability were found. This suggests that saplings from both provenances reacted similarly to drought events, at least at those stress levels to which they were exposed. Indeed, saplings from both provenances showed similar growth stability components (resistance and resilience indices) after the drought event of 2012. These results are also consistent with the lack of significant differences between provenances in terms of water relation traits. Resistance and resilience of forest tree species to drought can be due to plant functional traits related to water stress avoidance and tolerance. Water stress avoidance is related to hydraulic failure prevention via stomata closure (McDowell et al. 2008), and to the capacity of plants to reach deeper water sources, thanks to higher root-to-shoot ratios or faster growth rate (Padilla \& Pugnaire 2007, Villar-Salvador et al. 2012). In our study, the values of the measured water relation traits during the 2012 drought (higher SLA, $\Psi_{p d}$ and $E_{c}$, and lower RWC ) suggest that saplings avoided water stress, rather than adjusting their physiological response to precipitation levels.

Despite the lack of significant differences between provenances in water relation traits and growth stability components, sapling from the drier provenance showed greater growth rates. Ramírez-Valiente et al. (2011) found that Q. suber populations from drier sites showed a higher growth potential. Several studies with other broadleaved tree species have also reported greater growth rates in those individuals from drier provenances (Savva et al. 2007, Leland et al. 2016). The higher growth ca- pacity of drier provenances might allow rapid seedling establishment during the wet season and drought stress avoidance during summer drought (Villar-Salvador et al. 2012). Interestingly, mortality after plantation only occurred in saplings from the mesic provenance. On the other hand, eight years after planting saplings from the drier provenance were greater in diameter but similar in height than those from the mesic provenance. This might suggest a larger biomass allocation to roots in saplings from drier provenances, which in turn might explain its superior field performance (Matías et al. 2014). However, Bucharova (2017) argued that APM may have unpredictable effects on biotic interactions, recommending its implementation only if local provenances perform so poorly that they would fail to ensure ecosystem services. Given our results, the consideration of other options oriented to enhance plant performance and plant resilience to drought events should be explored.

As we stressed above, the major challenge facing Mediterranean forest plantations lies in surviving summer water stress during early life, especially the first years after planting (Villar-Salvador et al. 2004). In fact, saplings showed the lowest water potential in the summer following plantation, while the rest of water relation traits indicate a conservative water use strategy (lower SLA and $E_{c}$, and higher $R W C_{c}$ ). In summer 2012 (driest year), plants showed a better water status than in 2008 and 2009, possibly because their root system reached stable water reserves (Padilla \& Pugnaire 2007). Consequently, plants developed leaves with higher SLA (more leaf area per unit of invested biomass) and maintained longer stomatal opening (lower $\mathrm{RWC}_{\mathrm{c}}$ ), which resulted in maintaining some degree of growth under unfavorable environmental conditions. All this reinforces the need to put the focus on improving the probability of survival during the first years after planting, when plants are more vulnerable. Plant performance depends on a complex matrix where ecological factors interact with nursery and silvicultural practices to determine the success of a forest plantation. Plant quality, planting date, site preparation, and plantation management are among these practices (Grossnickle 2012, Löf et al. 2012). In the last decades, many studies in Mediterranean environments underline that plant out-planting performance increases with plant size (see Villar-Salvador et al. 2012). The superior out-planting performance of larger seedlings has been linked to their greater growth capacity during the wet season, which would allow them to growth roots deeper in the soil before the summer drought period (Villar-Salvador et al. 2012). In addition, increasing nutrient concentration of nursery Q. ilex seedlings enhances seedling size, root growth capacity, water relation parameters and out-planting performance (Villar-Salvador et al. 2004, Cues- ta et al. 2010, Andivia et al. 2014). On this basis, promoting size and nutrient content of nursery seedling are powerful tools to guarantee high survival levels in forest restoration projects in the Mediterranean region.

\section{Conclusions}

The incorporation of $Q$. ilex seedlings from drier provenances into forest restoration projects under mesic environmental conditions did not promote resilience to drought events but enhanced survival and growth. This, together with the lack of differences in water relation traits between provenances, suggests that the selection of plant material for forest plantation should be carefully evaluated considering the high intra- and inter-specific differences in the response of $Q$. ilex to water stress. On the other hand, our results indicate that the first year after planting is the critical period for the success of forest plantations. In this context, actions aimed to increase the early survival of seedling after planting, such as improving nursery plant quality or conducting an appropriated site preparation might be better alternatives than incorporating non-local genetic plant material. However, further studies are needed to evaluate the long-term response of different provenances to drought events. Studies in which water availability is experimentally manipulated would be of key interest to test the performance of different provenances to expected increase in the magnitude and frequency of drought events.

\section{Acknowledgments}

All authors contributed in the designing of the experiment. EA and FN conducted field and lab measurements. EA ran the data analysis and wrote the paper. FN, MF, RA and JVP revised the manuscript.

We gratefully thank the field assistance of Felipe Carevic and Rocío Macías. We thank Francisco Auñón and David Sánchez from CIFOR-INIA (Madrid, Spain) for providing the shapefiles of the Q. ilex provenance regions in Spain. We also thank the suggestions and comments of an anonymous reviewer.

This study was partially funded by the project ENCINUT (AGL2006-12609-C02-01/ FOR). EA is supported by the post-doctoral grants Ayudas para contratos para la formación postdoctoral (FPDI-2013-15573) from the Ministry of Economy of the Spanish Government.

\section{References}

Aitken SN, Whitlock MC (2013). Assisted gene flow to facilitate local adaptation to climate change. Annual Review of Ecology, Evolution and Systematics 44: 367-388. - doi: 10.1146/annu rev-ecolsys-110512-135747

Alía R, García del Barrio JM, Iglesias S, Mancha JA, De Miguel J, Nicolás JL, Pérez F, Sánchez de Ron D (2009). Regiones de procedencia de especies forestales en España [Provenances of 
Spanish forest species]. Organismo Autónomo Parques Nacionales, Madrid, Spain, pp. 363. [in Spanish] [online] URL: http://www.citeulike. org/group/15400/article/13758851

Andivia E, Carevic F, Fernández M, Alejano R, Vázquez-Piqué J, Tapias R (2012a). Seasonal evolution of water status after outplanting of two provenances of Holm oak nursery seedlings. New Forests 43: 815-824. - doi: 10.1007/s1 1056-012-9347-3

Andivia E, Fernández M, Vázque-Piqué J, Alejano $R$ (2012b). Two provenances of Quercus ilex ssp. ballota (Desf) Samp. nursery seedlings have different response to frost tolerance and autumn fertilization. European Journal of Forest Research 131: 1091-1101. - doi: 10.1007/s10342-011-05 78-1

Andivia E, Fernández M, Vázquez-Piqué J (2014). Assessing the effect of late-season fertilization on Holm oak plant quality: insights from morpho-nutritional characterizations and water relations parameters. New Forests 45: 149-163. - doi: 10.1007/s11056-013-9397-1

Bates D, Maechler M, Bolker B, Walker S (2015). Fitting linear mixed-effects models using Ime4. Journal of Statistical Software 67: 1-48. - doi: 10.18637/jss.v067.io1

Benito-Garzón M, Sánchez De Dios R, Sainz-Ollero $\mathrm{H}$ (2008). Effects of climate change on the distribution of Iberian tree species. Applied Vegetation Sciences 11: 169-178. - doi: 10.3170/20 08-7-18348

Benomar L, Lamhamedi MS, Rainville A, Beaulieu J, Bousquet J, Margolis HA (2016). Genetic adaptation vs. ecophysiological plasticity of photosynthetic-related traits in young Picea glauca trees along a regional climatic gradient. Frontiers in Plant Sciences 7: 48. - doi: 10.3389/ fpls.2016.00048

Biondi F, Qeadan F (2008). A theory-driven approach to tree-ring standardization: defining the biological trend from expected basal area increment. Tree-Ring Research 64: 81-96. - doi: 10.3959/2008-6.1

Bucharova A (2017). Assisted migration within species range ignores biotic interactions and lacks evidence. Restoration Ecology 25: 14-18. doi: $10.1111 /$ rec.12457

Bunn AG (2008). A dendrochronology program library in R (dpIR). Dendrochronologia 26: 115124. - doi: 10.1016/j.dendro.2008.01.002

Burnham KP, Anderson DR (2002). Model selection and multimodel inference: a practical information-theoretic approach. Springer-Verlag, New York, USA, pp. 488. - doi: 10.1007/b97636

Bussotti $F$, Pollastroni $M$, Holland $V$, Brüggemann W (2015). Functional traits and adaptive capacity of European forests to climate change. Environmental and Experimental Botany 111: 91-113. - doi: 10.1016/j.envexpbot.2014. 11.006

Cuesta B, Villar-Salvador P, Puértolas J, Jacobs DF, Benayas JMR (2010). Why do large, nitrogen rich seedlings better resist stressful transplanting conditions? A physiological analysis in two functionally contrasting Mediterranean forest species. Forest Ecology and Management 260: 71-78. - doi: 10.1016/j.foreco.2010.04. 002

Gimeno TE, Pías B, Lemos-Filho P, Valladares F (2008). Plasticity and stress tolerance override local adaptation in the responses of Mediterranean holm oak seedlings to drought and cold. Tree Physiology 29: 87-98. - doi: 10.1093/ treephys/tpnoo7

Giorgi F (2006). Climate change hot-spots. Geophysical Research Letters 33 (8): 89. - doi: 10.10 29/2006GL025734

Gratani L, Meneghini M, Pesoli P, Crescente MF (2003). Structural and functional plasticity of Quercus ilex seedlings of different provenances in Italy. Trees, Structure and Function 17: 515521. - doi: 10.1007/s00468-003-0269-8

Grossnickle SC (2012). Why seedlings survive: influence of plant attributes. New Forests 43: 711738. - doi: 10.1007/s11056-012-9336-6

Leland C, Hom J, Skowronsky N, Ledig FT, Krusic PJ, Cook ER, Martin-Benito D, Martín-Fernández J, Pederson N (2016). Missing rings, synchronous growth, and ecological disturbance in a 36-year pitch pine (Pinus rigida) provenance study. PLoS ONE 11 (5): e0154730. - doi: 10.1371/ journal.pone. 0154730

Lindner $M$, Fitzgerald JB, Zimmermann $\mathrm{NE}$, Reyer C, Delzon S, Van Der Maaten E, Schelhaas MJ, Lasch P, Eggers J, Van Der Maaten-Theunissen M, Suckow F, Psomas A, Poulter B, Hanewinkel $M$ (2014). Climate change and European forests: what do we know, what are the uncertainties, and what are the implications for forest management? Journal of Environmental Management 146: 69-83. - doi: 10.1016/j.jenvm an.2014.07.030

Löf M, Dey DC, Navarro RM, Jacobs DF (2012). Mechanical site preparation for forest restoration. New Forests 43: 825-848. - doi: 10.1007/s 11056-012-9332-x

Lloret F, Keeling EG, Sala A (2011). Components of tree resilience: effects of successive lowgrowth episodes in old ponderosa pine forests. Oikos 120: 1909-1920. - doi: 10.1111/j.1600-0706. 2011.19372.x

Marqués L, Camarero JJ, Gazol A, Zavala MA (2016). Drought impacts on tree growth of two pine species along an altitudinal gradient and their use as early-warning signals of potential shifts in tree species distributions. Forest Ecology and Management 381: 157-167. - doi: 10.101 6/j.foreco.2016.09.021

Matías L, González-Díaz P, Jump AS (2014). Larger investment in roots in southern range-edge populations of Scots pine is associated with increased growth and seedling resistance to extreme drought in response to simulated climate change. Environmental and Experimental Botany 105: 32-38. - doi: 10.1016/j.envexpbot.201 4.04.003

McDowell N, Pockman WT, Allen CD, Breshears DD, Cobb N, Kolb T, Plaut J, Sperry J, West A, Williams DG, Yepez EA (2008). Mechanisms of plant survival and mortality during drought: why do some plants survive while others succumb to drought? New Phytologist 178: 719739. - doi: 10.1111/j.1469-8137.2008.02436.x

Nakagawa S, Schielzeth H (2013). A general and simple method for obtaining $\mathrm{R}^{2}$ from generalized linear mixed-effects models. Methods in Ecology and Evolution 4: 132-142. - doi: 10.1111/j. 2041-210x.2012.00261.x

Padilla FM, Pugnaire FI (2007). Rooting depth and soil moisture control Mediterranean woody seedling survival during drought. Func- tional Ecology 21: 489-495. - doi: 10.1111/j.13652435.2007.01267.x

Pesoli P, Gratani L, Larcher W (2003). Responses of Quercus ilex from different provenances to experimentally imposed water stress. Biologia Plantarum 46: 577-581. - doi: 10.1023/A:1024823 830225

Pluess AR, Frank A, Heiri C, Lalagüe H, Vendramin GG, Oddou-Muratorio S (2016). Genomeenvironment association study suggests local adaptation to climate at the regional scale in Fagus sylvatica. New Phytologist 210: 589-601. doi: 10.1111/nph.13809

Quisenberry JE, Roark B, McMichael B (1982). Use of transpiration decline curves to identify drought tolerant cotton germplasm. Crop Sciences 22: 918-922. - doi: 10.2135/cropsci1982.001 1183X002200050004X

Ramírez-Valiente JA, Valladares F, Huertas AD, Granados S, Aranda I (2011). Factors affecting cork oak growth under dry conditions: local adaptation and contrasting additive genetic variance within populations. Tree Genetics and Genomes 7: 285-295. - doi: 10.1007/s11295-010-0 331-9

Rodá F, Retana J, Gracia CA, Bellot J (1999). Ecology of Mediterranean evergreen oak forests. Springer, Berlin, Germany, pp. 377. [online] URL: http://books.google.com/books?id=bOHj wKfcq2MC

Ruiz-Benito P, Lines ER, Gómez-Aparicio L, Zavala MA, Coomes DA (2013). Patterns and drivers of tree mortality in Iberian forests: climatic effects are modified by competition. PLoS ONE 8 (2): e56843. - doi: 10.1371/journal.pone.005 6843

Sánchez-Salguero R, Navarro-Cerrillo RM, Camarero JJ, Fernández-Cancio A (2012). Selective drought-induced decline of pine species in southeastern Spain. Climatic Change 113: 767785. - doi: 10.1007/s10584-011-0372-6

Savolainen O, Pyhäjärvi T, Knürr T (2007). Gene flow and local adaptation in trees. Annual Review of Ecology, Evolution and Systematics 38: 595-619. - doi: 10.1146/annurev.ecolsys.38. 091206.095646

Savva Y, Denneler B, Koubaa A, Tremblay F, Bergeron $Y$, Tjoelker MG (2007). Seed transfer and climate change effects on radial growth of jack pine populations in a common garden in Petawawa, Ontario, Canada. Forest Ecology and Management 242: 636-647. - doi: 10.1016/j.for ec0.2007.01.073

Scholander P, Hammel H, Bradstreet E, Hemmingsen E (1965). Sap pressure in vascular plants. Negative hydrostatic pressure can be measured in plants. Science 148: 339-346. - doi: 10.1126/science.148.3668.339

Schwartz MW, Hellmann JJ, Mclachlan JM, Sax DF, Borevitz JO, Brennan J, Camacho AE, CebalIos G, Clark JR, Doremus H, Early R (2012). Managed relocation: integrating the scientific, regulatory, and ethical challenges. BioScience 62 : 732-743. - doi: 10.1525/bio.2012.62.8.6

Valladares F, Martinez-Ferri E, Balaguer L, PerezCorona E, Manrique E (2000). Low leaf-level response to light and nutrients in Mediterranean evergreen oaks: a conservative resource-use strategy? New Phytologist 148: 7991. - doi: 10.1046/j.1469-8137.2000.00737.x Valladares F, Gianoli E, Gómez JM (2007). Ecolog- 
ical limits to plant phenotypic plasticity. New Phytologist 176: 749-763. - doi: 10.1111/j.14698137.2007.02275.x

Van Der Maaten-Theunissen M, Van Der Maaten $E$, Bouriaud O (2015). pointRes: an R package to analyze pointer years and components of resilience. Dendrochronologia 35: 34-38. - doi: 10.1016/j.dendro.2015.05.006

Vicente-Serrano S, Beguería S, López-Moreno Jl (2010). A multiscalar drought index sensitive to global warming: the standardized precipitation evapotranspiration index. Journal of Climate 23: 1696-1718. - doi: 10.1175/2009JCLI2909.1 Villar-Salvador P, Planelles R, Enriquez E, Peñuelas-Rubira JL (2004). Nursery cultivation regimes, plant functional attributes, and field performance relationships in the Mediterranean oak Quercus ilex L. Forest Ecology and Management 196: 257-266. - doi: 10.1016/j.for eco.2004.02.061

Villar-Salvador P, Puértolas J, Cuesta B, Penuelas JL, Uscola M, Heredia-Guerrero N, Benayas
JMR (2012). Increase in size and nitrogen concentration enhances seedling survival in Mediterranean plantations. Insights from an ecophysiological conceptual model of plant survival. New Forests 43: 755-770. - doi: 10.1007/ s11056-012-9328-6

Villar-Salvador P, Nicolás-Peragón JL, HerediaGuerrero N, Uscola M (2013). Quercus ilex L. In: "Producción y Manejo de Semillas y Plantas Forestales. Tomo II" [Production and management of forest seeds and plants. Volume II] (Pemán J, Navarro-Cerrillo RM, Nicolás JL, Prada MA, Serrada R eds). Organismo Autónomo Parques Nacionales, Madrid, Spain, pp. 226250. [in Spanish] [online] URL: http://www. researchgate.net/publication/259196301

\section{Supplementary Material}

Fig. S1 - Q. ilex saplings from two contrasting provenances eight year after the plantation in a common garden.
Fig. S2 - Diameter distribution of all Q. ilex saplings (a) and for each provenance (b) eight year after the plantation in a common garden.

Fig. S3 - Standardized Precipitation Evapotranspiration Index (SPEI) at the plantation location for the period 2002-2016.

Fig. S4 - Boxplot for the height and diameter of Q. ilex saplings from two contrasting provenances eight year after the plantation in a common garden.

Tab. S1 - Mean ( \pm SE) values for the water status parameters $Q$. ilex sapling from two contrasting provenances measured in midJuly in 2008, 2009, 2011 and 2012.

Link: Andivia_2573@supplo01.pdf 